less opportunity to turn to teaching. Unconscious cheating, wishful thinking (which is universal), unsound experimental design and analysis, and seeing what we expect are further pitfalls. The statistician M. G. Kendall once described the phenomenon of seeing what one expects as "one of the deadliest forms of bias in psychology”. He was referring to an experiment in which an observer of a reliable random-number generator had a tendency to write down too many even numbers.

Potentially the most important evidence in Radin's book is in the chapter on metaanalysis, which is also emphasized in the introduction - and it is here that the 'filedrawer' effect comes into play.

Meta-analysis is the combination of results from many experiments. A problem in meta-analysis, and in statistics generally, is how to allow for the researches that remain unpublished and unknown because their $P$ values did not reach a conventional significance level such as 0.05 . I do not know who coined the name 'file-drawer' effect for this problem. This effect drags down the statistical significance of published work. Radin claims that "parapsychologists were among the first to become sensitive to this problem" — although he does not say when - and he mentions that "in 1975 the Parapsychological Association's officers adopted a policy opposing the selective reporting of positive outcomes". The problem was known to statisticians by 1958 .

Consider the following typical example. Radin points out that there were 186 publications on ESP card tests worldwide from 1882 to 1939 . "The combined results of this four-million trial database [taken at face value]," he says, "translate into tremendous odds against chance - more than a billion trillion to one." (A 'trial' is the guess of one card.) He means that the $P$ value is about $10^{-21}$ - he is not writing only for the scientific establishment. This $P$ value corresponds to a bulge above 'chance' expectation of $9.5 \sigma$, where $\sigma$ is the standard deviation. (I call that a 'sigmage' of 9.5.)

Apart from the possibility of conscious and unconscious fraud and wishful thinking in some fraction of the publications, Radin claims, with no explanation, that, in order to "nullify" the statistical significance, the file drawer would have to contain "more than 3,300 unpublished, unsuccessful reports for each published report". That number 3,300 is a gross overestimate. It should be reduced at least to about 15 (or even to 8).

The expected sigmage in the file drawer, under the null hypothesis, would be slightly negative but I will call it zero. If these results were combined with the published work, the total sample size would be multiplied by 16 , thus becoming 64 million individual guesses. Given the null hypothesis ('chance'), the bulge would be unaffected so the sigmage would be divided by $\sqrt{ } 16=4$ and would become $9.5 / 4=2.4$, with a $P$ value of about $1 / 100$.

Because the number of individual guesses is so large, this $P$ value appreciably supports the null hypothesis (no ESP). This is because a Bayes factor (the factor by which the odds of a hypothesis are multiplied in the light of the observations), corresponding to a fixed $P$ value, is roughly proportional to $1 / \sqrt{ } \mathrm{N}$, where $\mathrm{N}$ is the sample size. So Radin's method for evaluating the file-drawer effect, whatever that method may be, must be misguided. This conclusion largely undermines Radin's meta-analysis which is central to his case for ESP.

Nevertheless, Radin's book is well written and provides a good summary of the arguments supporting the existence of ESP, with about 600 references. It is less good on the counter-arguments. Readers should also consult ESP and Parapsychology: A Critical Evaluation by C. E. M. Hansel (Buffalo, 1980), where much fraudulent work is exposed. Radin quotes Hansel as saying that three $P$ values, each of 0.01 , amount to one of $10^{-6}$, and that he (Radin) would find that convincing. But the product of independent $P$ values is not a $P$ value. The product has to be transformed by a method due to R. A. Fisher. Both Hansel and Radin have overlooked this. In the present example, the composite $P$ value is $1 / 9,000$, not $1 / 1,000,000$.

I am not a sceptic by definition. There is one type of experiment that could convince me if it were successful. Guesses, by psychics, of the parities (even or odd) of future cricket scores could be published on the World Wide Web. The actual scores and parities could be published (later) in large print to help the

\section{Toy review Smaller, che}

With Christmas still months away, and the latest Mars landing already fading in the memory, it is a good time to draw your attention to this scientific stocking-filler. In collaboration with the US Jet Propulsion Laboratory, Mattel has brought out the "Mattel Hot Wheels JPL Sojourner Mars Rover Action Pack Set".

This is a set of three small plastic models: the Pathfinder spacecraft in transit, with removable heat shield and tiny lander; a larger-scale version of the lander, with foldable panels and removable rover; and a larger-scale-still Sojourner rover. The rover is undoubtedly the star, with sprung 'rocker-bogey' suspension that allows it to take up all sorts of cute rock-sniffing postures.

The Nature review copy of the Mattel Hot Wheels JPL Sojourner Mars Rover Action Pack Set has now completed its primary mission objectives, successfully demonstrating the technology involved in operating for several weeks on top of a computer screen in a harsh environment of editorial curiosity, without suffering any appreciable reduction in its

precognizing of the psychics and to help their evaluation. This procedure would rule out the possibility of undetectable fraud.

I. J. Good is in the Department of Statistics,

Virginia Polytechnic Institute and State University, Blacksburg, Virginia 24061-0439, USA.

\title{
Dangerous liaisons
}

\section{Menachem's Seed \\ by Carl Djerassi \\ University of Georgia Press: 1997. Pp. 196. \\ $\$ 21.95$}

\section{Jack Cohen}

This is the third novel in a series of what the chemist Carl Djerassi calls "science-infiction" in which everything mentioned could or does exist. "Most of my characters, fictional as well as real, are scientists," he says. "By exposing their lives, I try to make comprehensible the culture and behaviour of scientists."

There is a similar, specialized genre on the fringes of modern science fiction - stories about fictional scientists like fictional detectives or even fictional cowboys. Carl Sagan's Contact is a well known example, but Gregory Benford's Timescape or Artefact, Greg Bear's Blood Music, as well as Nigel Kneale's older Quatermass series or even E. E. 'Doc' Smith's archaic Lensman all come to mind as fiction about scientists. Science-infiction, however, seems to be less exciting and to have fewer possibilities.

I reviewed elsewhere the first of Djerassi's novels, Cantor's Dilemma, and recommended it, mainstrean

\section{heaper, more plasticky}

operational parameters. And at $\$ 5$ initial outlay (only available in the United States, at pre it is certainly in keeping with NASA's new

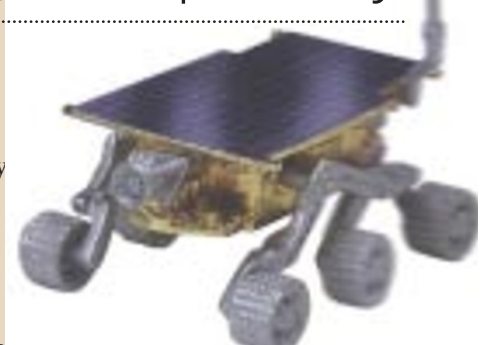
economical philosophy.

But for those who hark back longingly to the old days of expensive, 'gold-plated' missions, an expensive, literally gold-plated model of Sojourner is available (for \$49.99). It “is mounted on a silver base plate molded to resemble the martian surface and has a handsome brass identification plate". Surely a must for every mantelpiece.

Stephen Battersby is an assistant editor of Nature. 
time the science is much closer to my own expertise (human reproductive technology, especially intracytoplasmic sperm insertion) and I am familiar with many of the locations and personality types; I looked forward to recognizing more of the events, and expected more action.

On the surface, this is a lubricious novel about an affair between an Israeli, Menachem Dvir, formerly an atomic engineer and physicist but now a research administrator at Ben-Gurion University in Beersheba, and an American widow, Melanie Laidlaw, a grant administrator for a foundation wishing to promote sophisticated male contraception.

Conforming to the stereotype of the 'able woman administrator', she is apparently attracted to him only because she suspects most men of wanting grant-money; he, on the other hand, has not heard of her foundation and is hooked by her charms alone.

Thoughtful flashbacks that illuminate the story are recounted in pages of italics, with occasional lapses into didacticism: her masturbatory history and his sexual anatomy are relished in explicit descriptions more informative than any genuine streamof-consciousness could possibly be. There is some excuse, however: such science as there is concerns the involvement of nitric oxide in penile erection, and the plot climax involves her secretly stealing his sperm for her own fertilization. I can't tell whether a physicist or a florist would follow the science, but on the whole it is accurate and sets the scene convincingly.

Much of the drama takes place at a fictional series of "Kirchberg Conferences on Science and World Affairs", explicitly modelled on the Pugwash meetings. This gives Djerassi the chance to evoke the early days of Ben-Gurion University and its relation to Dimona atomic research, and to portray a Palestinian scientist's progressive interaction with Menachem against the background of atomic power and weapons in the recent Middle East.

The descriptions of cameo parts are also good, and personal vignettes scattered across the broad canvas are effective in adding colour. The writing is authoritative, evocative but spare; conversation is frequently stilted — but probably justifiably so considering the subject matter being discussed.

There are a few surprising technical and linguistic infelicities: she drops his semen directly into a Dewar flask of liquid nitrogen, without cryoprotectant; an internationally famous French scientist fails to translate mauvais nouvelles as bad news; and I can't quite believe that a New England society matron, at a fund-raising dinner in Boston, would use the word 'prick' in the way it is used here. Worst, Menachem's reason for not wanting a child - he has been exposed to heavy radiation - has important implica- tions even if an apparently normal spermatozoan is used for fertilization. But Djerassi ignores these.

Scientists active on the conference circuit will probably find the portrayal here true to life, and also learn about Israel and human reproduction - although not much about how to conduct an affair. Scientists who resent not being asked to such conferences will have their prejudices confirmed - all drinking and politics.

In an afterword, Djerassi says he tried hard to create an authentic ambience. He has succeeded, but that does not necessarily make the novel entertaining or mean that it will enhance the public image of science or scientists. Indeed, the whole package is rather too predictable, including the cover showing Leonardo da Vinci's Coition of Hemisected Man and Woman. Even though scientists in science fiction have a tendency to blow up the world in exciting ways, their lives are a lot more fun.

Jack Cohen is at the Centre for Ecosystem Analysis and Management, University of Warwick, Coventry CV4 7AL, UK.

\section{Sun, sea and life}

\section{Aquatic Photosynthes is}

by Paul G. Falkowski and John A. Raven Blackwell Science: 1997. Pp. 375. £39.50, $\$ 54.95$

\section{Egilsakshaug}

"Terrestrial plants are so much part of the human experience that aquatic photosynthetic organisms are often overlooked," say the authors. It may be added that the great diversity of pigment composition and physiological properties among aquatic photosynthetic organisms, together with the fact that they are responsible for about 40 per cent of Earth's net primary production, more than justifies publication of this book.

The authors succeed in their aim of integrating knowledge from biophysics, biochemistry and physiology and applying it in an ecological and evolutionary context.

An introductory account, the book presents a wide range of topics: the introduction deals with basic photosynthetic chemistry, evolution and diversity of algae, structural and chemical properties of photosynthetic cells and useful information on quantum aspects of light, electron-spin states, energy transfer in photosystems, fluorescence and much more. The bulk of the book deals with photosynthesis proper, photosynthetic models, respiration and biosynthesis. And there are concluding chapters on global primary production, its modelling on the basis of satellite measurements of chlorophyll $a$, and the role of photosynthesis in biogeochemical cycles and past and present global change.

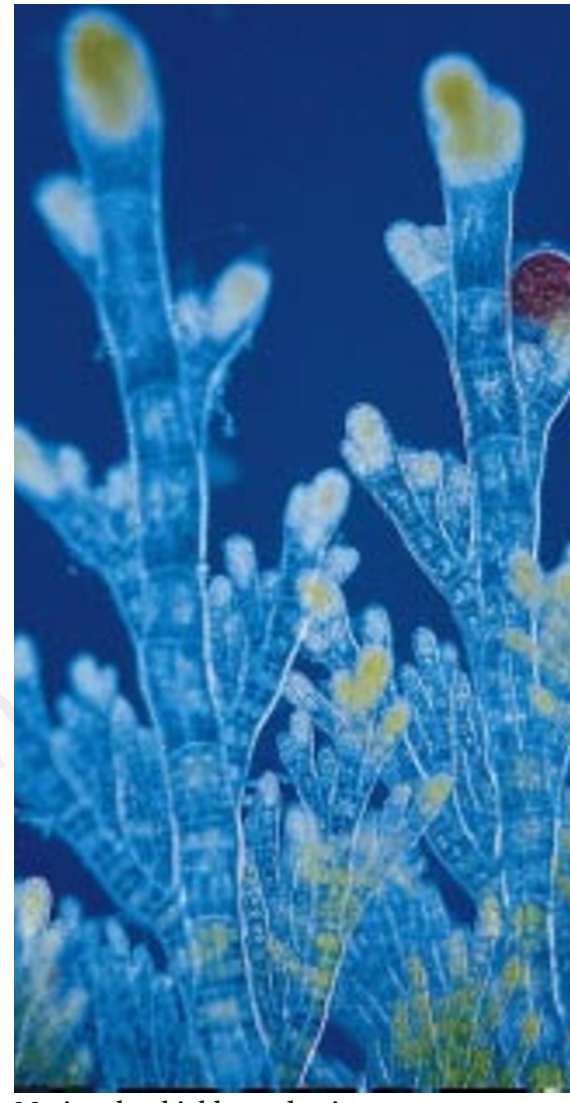

Marine alga: highly productive en masse.

The emphasis of the book is on marine photosynthesis, as reflected in the many references to the authors' own excellent studies. But photosynthesis in freshwater algae does not differ essentially from that in marine algae. Planktonic algae, including cyanobacteria, are given broad coverage whereas seaweeds are treated cursorily. Errors are immaterial and few and far between. A rare exception is the description of light-harvesting complexes in peridinin-containing dinoflagellates, which is incorrect.

Complex phenomena are admirably well described, the layout is appetizing and the illustrations instructive. The historical background is well covered, and numerous footnotes offer anecdotes and facts that make vivid reading. How many biologists know that the term 'photon' was coined by the famous chemist Gilbert Lewis and that Lord Rayleigh developed his theory of lightscattering while travelling down the Nile on honeymoon?

This enjoyable book is recommended to anyone with a general scientific background and an interest in aquatic photosynthesis and its role in biogeochemical cycles and climate. Students who specialize in aquatic photosynthesis should supplement this excellent work with texts on aquatic optics and general plant physiology.

Egil Sakshaug is at the Biological Station, Norwegian University of Science and Technology in Trondheim, Bynesv. 46, N-7018 Trondheim, Norway. 